\title{
Intensity of nursing work in public hospitals*
}

\author{
Tatiane Araújo dos Santos ${ }^{1}$ \\ (D) https://orcid.org/0000-0003-0747-0649 \\ Handerson Silva Santos ${ }^{1}$ \\ (iD) https://orcid.org/0000-0002-4324-8888 \\ Elieusa e Silva Sampaio \\ (D) https://orcid.org/0000-0003-1702-7296 \\ Cristina Maria Meira de Melo ${ }^{1}$ \\ (D) https://orcid.org/0000-0002-8956-582X \\ Ednir Assis Souza ${ }^{1}$ \\ (iD) https://orcid.org/0000-0001-5845-6527 \\ Cláudia Geovana da Silva Pires \\ (D) https://orcid.org/0000-0001-9309-2810
}

Objective: to analyze the intensity of nursing work in public hospitals. Method: cross-sectional, quantitative study, carried out in 22 public hospitals. The sample was composed of 265 nurses and 810 nursing technicians and assistants. Data were collected through a questionnaire and analyzed with Exploratory Factor Analysis. The calculation of the distribution of the work intensity by category was done using a score ranging from -1 to +1 standard deviation of the data. Fisher's exact test $(0.05<\mathrm{p} \leq 0.10)$ was used to observe the significance between groups according to the employment bond. Results: work intensity contributed to the explanation of precarization of work, with a value of $13 \%$ for nurses and $51.2 \%$ for technicians and assistants. For the technicians and assistants, the variables with the highest factor loadings were 'work requires more than she can do' (0.6696) and 'takes on multiple tasks due to staff shortages' (0.6156). Among nurses, the highest factor loadings were observed in the variables 'time pressure at work (0.6779) and 'Work pace' (0.6651). Conclusion: the variables analyzed indicate that work intensity occurs differently among nursing workers, and is revealed by the versatility, understaffing and flexibility of work.

Descriptors: Work; Nursing; Nurses; Nurses' Aides; Licensed Practical Nurses; Hospitals, Public.

\section{How to cite this article}

Santos TA, Santos HS, Sampaio ES, Melo CMM, Souza EA, Pires CGS. Intensity of nursing work in public hospitals. Rev. Latino-Am. Enfermagem. 2020;28:e3267. [Access _ † †] ; Available in: DOI: http://dx.doi.org/10.1590/1518-8345.3221.3267. month day year 


\section{Introduction}

Control over work time has always been the focus of employers in capitalist society. The class that owns the means of production seeks to control this time, enforcing the idea that it is quantitative and rational. This ideological construction is deemed as universal and as the standard in modern society ${ }^{(1)}$.

To understand the use of work time in the perspective of the employer, it is necessary to address its three dimensions: duration of this time (working hours), distribution of the time and work intensity. Duration of working hours refers to the total time of work. It is the most perceptible dimension and, for this reason, it is at the center of the conflict between unions and employers. The distribution of working time is its organization in days, weeks, months, years. This distribution includes intermittent work, compensatory time, home office or remote work and all the free time used to gain qualifications for work ${ }^{(2-3)}$.

Work intensity is a term that still does not have a consensual definition in the field of sociology of work. In this article, the definition used was "intensity is the effort made by workers to meet the constraints of work organization during a unit of time"(2).

Therefore, work intensity does not only mean extending working hours, but refers to the worker's ability to produce more work on the same workday. For this reason, this intensity is difficult to be perceived, as it is necessary to investigate the constraints that lead the worker to spend more physical, psychological, mental, social, cultural and relational energy during their work ${ }^{(1-3)}$.

It should be noted that work intensity has an uneven impact on outsourced and permanent employees and on men and women, as the latter are subject to more intense work $^{(3-5)}$. Considering that the professional field of nursing in Brazil is composed mainly of women(6), the authors of the present study choose to use feminine terms to give visibility to the intensity of women's work.

Work intensity is also revealed by fast workflows, in which the chain of activities must be done quickly to not disrupt the continuous flow of collective work. Intense work and fast workflows are increasingly common in hospitals and are related to the way work is organized (4-5). The work organization model in nursing combines characteristics of toyotism and taylorism, which contributes to the intensification of work and subjects' workers to organizational constraints.

Intense work and fast workflow are characteristics of nursing work ${ }^{(4-5)}$. Studies reveal that work intensity has serious consequences for the nursing staff, such as professional errors, work accidents and physical and psychological illness ${ }^{(7-10)}$.

Intensity is a form of precarization of labor. The enforcement of goals, extended working hours and the necessity for versatility of the worker are aspects related to intensity that hinder work relationships and work conditions. It should be mentioned that all these aspects are supported by fear-based management and moral harassment, which compels workers to submit themselves to the intensity of work $^{(3,11)}$.

In a review of the state-of-the-art studies on work intensity on the Virtual Health Library platform, limited to publications between the years 2015 and 2018 , due to the increase of publications on this topic in this period, using the boolean operator "and" and accepting only full text articles, a total of 13 articles addressing the intensity of nursing work were found. However, these articles address work intensity as one of the factors related to stress or illness of the nursing worker, without relating it to the contemporary situation of precarization of labor.

That said, the objective of this article is to analyze the intensity of nursing work in public hospitals.

\section{Method}

This is a cross-sectional, quantitative study, carried out in 15 (fifteen) public hospitals directly administered by the Health Secretariat of the State of Bahia and 7 (seven) hospitals indirectly administered by this Office. The hospitals agreed to participate in the research and provided records with the number of nurses, nursing technicians and nursing assistants.

The software STATA version 11 was used to estimate the size of the population, considering the information provided in the records mentioned above. As the prevalence of the studied phenomenon was unknown $(p=0.50)$, sampling error was set at $3 \%$ $(d=0.03)$ and confidence interval at 95\% $(a=0,05)$. The total elements in each stratum corresponded to the total number of nursing workers registered in organizations with direct management $(n=7,140$, with 1,712 nurses, 2,597 nursing technicians and 2,831 nursing assistants) and indirect management ( $n=1,681$, with 436 nurses, 1,160 nursing technicians and 85 assistants).

The stratified sampling with proportional allocation of workers was calculated according to the type of administration, work category and employment bond, totaling 265 nurses $(n=161$ permanent and $n=104$ outsourced) and 810 nursing technicians and assistants ( $n=597$ permanent and $n=213$ outsourced). 
Data was collected between March 2016 and February 2017 by the researchers and fellowship holders of the research group. The technique used for data collection was a survey conducted with a questionnaire containing 96 questions divided into seven sessions: I. Socio-demographic characteristics, II. Information on other employment bonds; III. Information on this work; IV. Information on the work process; V. Information on working conditions; VI Information on domestic activities and VII. Information on salary. The elaboration of the instrument was supported by an extensive literature review, the experience of nurses working in health organizations and instruments used in other studies.

The instrument validation process occurred from January to February 2015, with 347 workers from a hospital organization that was not included in the sample but had characteristics similar to those expected in the data collection fields. There was a need to change the wording of some questions to facilitate understanding. The collection instrument was also validated in multiple workshops, in which nursing workers and nurses with expertise on nursing work participated. There was subsequent guidance from a professional specialized in statistics.

The selection system adopted was direct approach to active workers in their respective sectors. Inclusion criteria were: nurses, nursing technicians and nursing assistants with more than 6 months of work $^{(12)}$ in the health institution and being able to answer the questions, that is, understanding what is being asked, considering that this ability is not necessarily related to the level of education.

Exploratory Factor Analysis (EFA) was used for data analysis. This method allows to reduce data, looking for latent variables (factors) that have high explanatory power in relation to the object of study. The main reasons for the use of EFA are the validation of the results of an evaluation and the development of a theory, since it grasps the construct and the synthesis of its relationships, resulting in factors that can be used in other analyzes ${ }^{(13)}$.

The following steps were followed for the use of EFA: 1. Based on a study on the typologies of the precarization of labor ${ }^{(11)}$, variables were allocated to the construct 'work intensity', building a factorial matrix; 2 . The matrix was factored according to the category of the worker and type of employment bond. The Kaiser-MeyerOlkin (KMO) test was performed, obtaining a global score of 0.8307 for nurses and 0.8794 for nursing technicians and assistants. Cronbach's alpha coefficient was used to validate the internal consistency of the variables; the global score of the nurses' matrix was 0.8822 , while the matrix of technicians and assistants obtained a score of 0.8839 , which indicate high homogeneity of responses.

The scree test was used for the extraction of the factors. Factor rotation was resumed with a factor loading cutoff of 0.40 . Subsequently, two methods of orthogonal factor rotation, with the varimax method, and one oblique rotation, with the promax method, were tested, with 4, 5 and 6 factors each, respectively. The researchers were responsible for deciding whether to use the matrix with 4, 5 or 6 factors, and if they should be dependent or independent.

After factoring, among the 96 initial variables, 11 remained in the nurses' matrix and 13 in the nursing technicians and assistants' matrix for the 'work intensity' construct.

The factor loading was calculated to assess the contribution of variables to the explanation of the construct 'work intensity'. Eigenvalue, difference, explanation ratio, cumulative and uniqueness were calculated to verify how the work intensity contributed to the construct 'precarization of labor'. These matrixes were discussed and evaluated in six moments with experts on nursing work, precarization of labor, epidemiology and statistics.

After the definition of the matrix of work intensity by the organization of the work process, the median, quartile $1(\mathrm{Q} 1)$ and quartile $3(\mathrm{Q} 3)$ were calculated to analyze the workers' responses. A Likert scale with the alternatives $1=$ never, 2 = rarely, $3=$ sometimes, $4=$ frequently and 5 = always was used.

In order to observe how work intensity was distributed by type of employment bond and by category of worker, a score ranging from -1 to +1 regarding the standard deviation (SD) of the data was created and the Fisher's exact test $(0.05<p \leq 0.10)$ was used to calculate the significance between the groups according to the employment bond. Thus, the category work intensity by the organization of the work process can present three scores: $<=-1$ SD low intensity; > -1SD and < + 1SD intermediate intensity; $>+1$ SD high intensity.

This study followed the ethical precepts established in Resolution no. 466/12 of the National Health Council and was assessed and approved by the Research Ethics Committee of the Nursing School of the Federal University of Bahia, protocol 398.772/2013.

\section{Results}

The study participants are mostly female (nurses: 90.1\%; technicians and assistants: $86.9 \%$ ), in the age group of 31 to 55 years (nurses: $76.9 \%$; technicians and assistants: $82,9 \%$ ), with 6 to 15 years of experience 
in the profession (nurses: 79.8\%; technicians and assistants: $48.1 \%$ ) and of black ethnicity (nurses: 83.9\%; technicians and assistants: $91.3 \%$ ).

The proportion calculation shows that work intensity contributes with $51.2 \%$ of the explanation of the precarization of labor for nursing technicians and assistants (Eingevalue: 7.75547; Difference: 5.87457; Cumulative: 0.5198 ). For nurses, this proportion is 13.0\% (Eingevalue: 2.06570; Difference: 0.20992; Cumulative: 0.5974 ).

Table 1 shows that, for nursing technicians and assistants, the variables related to the execution of care work have the highest factor loading. Some variables have a negative factor loading, which indicates a reverse impact on the factor, that is, they are present in daily work but are not considered relevant to work intensity.

The Quartiles for nursing technicians and assistants showed a difference in two variables when comparing the groups of permanent and outsourced workers. In the variable 'takes on multiple tasks due to staff shortages', Q3 is higher for permanent workers ( $5=$ always) than for outsourced workers ( $4=$ frequently). In the variable 'cares for more patients than she is capable of', Q3 is higher ( $5=$ always) for the group of outsourced workers than for permanent workers ( 4 =frequently) (Table 1 ).

Table 1 - Factor Loading, Quartiles (Q1* and $\mathrm{Q}^{+}$) and medians of the work intensity variables, nursing technicians and assistants $(n=810)$. Bahia, Brazil, 2016-2017

\begin{tabular}{|c|c|c|c|c|c|c|c|}
\hline \multirow{2}{*}{ Work intensity variables } & \multirow{2}{*}{ Factor loading } & \multicolumn{3}{|c|}{ Permanent } & \multicolumn{3}{|c|}{ Outsourced } \\
\hline & & Q1* & Median & Q3 $^{\dagger}$ & Q1* & Median & Q3 $^{\dagger}$ \\
\hline Work requires more than she can do & 0.6696 & 2 & 3 & 4 & 2 & 3 & 4 \\
\hline Takes on multiple tasks due to staff shortages & 0.6156 & 2 & 3 & 5 & 2 & 3 & 4 \\
\hline Cares for more patients than she is capable of & 0.5844 & 2 & 3 & 4 & 2 & 3 & 5 \\
\hline Time pressure at work & 0.5518 & 3 & 3 & 4 & 3 & 3 & 4 \\
\hline Work pace & 0.5251 & 3 & 4 & 5 & 3 & 4 & 5 \\
\hline Does activities that are not her responsibility & 0.4804 & 2 & 3 & 4 & 2 & 3 & 4 \\
\hline Does many things she doesn't agree with & 0.4551 & 2 & 3 & 3 & 2 & 3 & 3 \\
\hline Feels pressured by her boss to complete tasks & 0.4542 & 1 & 2 & 3 & 1 & 2 & 3 \\
\hline Does activities for which she was not trained & 0.4328 & 1 & 2 & 3 & 1 & 2 & 3 \\
\hline Tasks are interrupted before she can complete them & 0.4323 & 1 & 2 & 3 & 1 & 2 & 3 \\
\hline Rest breaks during the workday & -0.4510 & 2 & 3 & 4 & 2 & 3 & 4 \\
\hline $\begin{array}{l}\text { Work allows the development of activities and the achievement of goals } \\
\text { in a calm manner }\end{array}$ & -0.4863 & 2 & 3 & 4 & 2 & 3 & 4 \\
\hline Eats calmly during the workday & -0.5046 & 2 & 3 & 4 & 2 & 3 & 4 \\
\hline
\end{tabular}

${ }^{*}$ Q1 $=$ Quartile $1 ;{ }^{\dagger} \mathrm{Q} 3$ = Quartile 3

For nurses, the highest factor loading is in the variable related to time pressure to perform tasks, that is, nurses feel that they have less time to perform an increasing number of tasks (Table 2).

Differences in responses between the groups of permanent and outsourced workers are expressed in six variables. In the variable 'work pace', the median of the responses of permanent workers was 5 (always), while for outsourced workers it was 4 (frequently).

In the variable 'work requires more than she can do', the Q1 for permanent nurses was 2 (rarely), while for outsourced nurses it was 3 (sometimes). For $25 \%$ of permanent workers, the variable 'takes on multiple tasks due to staff shortages' is a situation that occurs rarely (2). For outsourced nurses, this condition occurs sometimes $(\mathrm{Q} 1=3)$.

'Supervision of more workers than they are capable' never occurs for $25 \%$ of permanent workers $(\mathrm{Q} 1=1)$. For outsourced workers, this situation rarely occurs $(\mathrm{Q} 1=2)$. For $75 \%(\mathrm{Q} 3)$ of the permanent workers, 'tasks are often interrupted before they can complete them'; for outsourced workers, this happens sometimes $(\mathrm{Q} 3=3)$. Permanent nurses rarely (Median $=2$ ) 'pause to rest during work', while outsourced nurses do it sometimes (3).

Regarding the scores of precarization variable by intensity by the organization of the work process (Table 3), there is no statistically significant difference between the groups of permanent and outsourced workers for nursing technicians and assistants $(p=0.431)$. However, when analyzing proportions, it is observed that outsourced workers are more frequently in the intermediate $(62.0 \%)$ and high $(21.6 \%)$ strata than permanent nursing technicians and assistants (intermediate $=60.5 \%$ and high $=19.3 \%$ ).

There is also no statistically significant difference between the proportions of the groups of permanent and outsourced nurses $(p=0.449)$ for the work intensity score (Table 4). However, there's a higher proportion $(21.7 \%)$ of permanent nurses in the high stratum of work intensity than of outsourced nurses (15.4\%). 
Table 2 - Factor Loading, Quartiles (Q1* and $\left.\mathrm{Q}^{+}\right)$and medians of the work intensity variables, nurses $(n=265)$. Bahia, Brazil, 2016-2017

\begin{tabular}{|c|c|c|c|c|c|c|c|}
\hline \multirow{2}{*}{ Work intensity variables } & \multirow{2}{*}{ Factor Loading } & \multicolumn{3}{|c|}{ Permanent } & \multicolumn{3}{|c|}{ Outsourced } \\
\hline & & Q1* & Median & Q3 $^{\dagger}$ & Q1* & Median & Q3 $^{\dagger}$ \\
\hline Time pressure at work & 0.6779 & 3 & 3 & 4 & 3 & 3 & 4 \\
\hline Work pace & 0.6651 & 4 & 5 & 5 & 4 & 4 & 5 \\
\hline Work requires more than she can do & 0.6052 & 2 & 3 & 4 & 3 & 3 & 4 \\
\hline Cares for more patients than she is capable of & 0.5700 & 3 & 4 & 5 & 3 & 4 & 5 \\
\hline Takes on multiple tasks due to staff shortages & 0.5494 & 2 & 4 & 4 & 3 & 4 & 4 \\
\hline Supervises more workers than she is capable & 0.4307 & 1 & 3 & 4 & 2 & 2 & 4 \\
\hline Tasks are interrupted before she can complete them & 0.4140 & 2 & 3 & 4 & 2 & 3 & 3 \\
\hline Repetitive gestures & 0.4039 & 3 & 4 & 5 & 3 & 4 & 5 \\
\hline Rest breaks during the workday & -0.4589 & 1 & 2 & 3 & 1 & 3 & 3 \\
\hline $\begin{array}{l}\text { Work allows the development of activities and the achievement of } \\
\text { goals in a calm manner }\end{array}$ & -0.4946 & 2 & 3 & 3 & 2 & 3 & 3 \\
\hline Eats calmly during the workday & -0.5517 & 2 & 3 & 4 & 2 & 3 & 4 \\
\hline
\end{tabular}

*Q1 = Quartile $1 ;{ }^{+} \mathrm{Q} 3$ = Quartile 3

Table 3 - Work intensity score for nursing technicians and assistants, according to type of employment bond. Bahia, Brazil, 2016-2017

\begin{tabular}{|c|c|c|c|c|c|}
\hline \multirow{2}{*}{ Work intensity score } & \multicolumn{2}{|c|}{ Permanent } & \multicolumn{2}{|c|}{ Outsourced } & \multirow[t]{2}{*}{ p-value } \\
\hline & $\mathbf{N}$ & $\%$ & $\mathbf{n}$ & $\%$ & \\
\hline$<=-1 S D^{*}$ low & 121 & 20.3 & 35 & 16.4 & \multirow{4}{*}{0.431} \\
\hline$>-1 \mathrm{SD}^{*}$ and $<=+1 \mathrm{SD}^{*}$ intermediate & 361 & 60.5 & 132 & 62.0 & \\
\hline$>+1 \mathrm{SD}^{*}$ high & 115 & 19.3 & 46 & 21.6 & \\
\hline Total & 597 & 100.0 & 213 & 100.0 & \\
\hline
\end{tabular}

*SD = Standard deviation

Table 4 - Work intensity score for nurses, according to type of employment bond. Bahia, Brazil, 2016-2017

\begin{tabular}{lccccc}
\hline \multirow{2}{*}{ Work intensity score } & \multicolumn{2}{c}{ Permanent } & \multicolumn{2}{c}{ Outsourced } & p-value \\
\cline { 2 - 6 } & $\mathbf{N}$ & $\%$ & $\mathbf{n}$ & $\%$ & \\
\hline$<=-1 \mathrm{SD}^{*}$ low & 28 & 17.4 & 19 & 18.3 & \\
$>-1 \mathrm{SD}^{*}$ and $<=+1 \mathrm{SD}^{*}$ intermediate & 98 & 60.9 & 69 & 66.3 & 0.449 \\
$>+1 \mathrm{SD}^{*}$ high & 35 & 21.7 & 16 & 15.4 & \\
Total & 161 & 100.0 & 104 & 100.0 & \\
\hline
\end{tabular}

*SD $=$ Standard deviation

\section{Discussion}

According to the definition of intensity ${ }^{(2)}$ used in this article, workers use their workforce to tackle the deficits and constraints of the health organization and enable the continuity of care, which is an evidence of the intensity of their work.

The work intensity matrixes reveal the distinct positions of workers within the work process. For nursing technicians and assistants, the variables related to direct assistance to the user obtained the highest factor loadings. This means that these workers are more prone to illness and care errors due to their high workload(14-15).

For nurses, the variables reflected the position in management and care that these professionals occupy in the nursing work process. For these professionals, work intensity has an impact on decision making, compromising the management part of their work. In addition, the performance of care and management activities at the same time makes nurses more prone to perceive the intensity of their work ${ }^{(16-17)}$.
Work intensity is one of the aspects of precarization of labor, which has the objective of dominating the worker through fear ${ }^{(11)}$, based on the new demands of the current model of production - toyotism - which requires versatility, multifunctionality and flexibility. In the current context, being flexible and multifunctional means accepting changes in the short term, meeting the demands of the employer with agility, taking risks, negotiating at work without being based on rules and regulations, being available at all times for work demands or training using free time ${ }^{(1,3)}$. As a result, work intensity adds to the vulnerability of new forms of hiring, unhealthy working conditions and loss of labor rights, which increases and reinforces the precarization of labor.

Studies in the field of sociology reveal that precarization of labor does not occur evenly among workers. Women, black men and women, young adults and outsourced workers are more vulnerable to this phenomenon and, therefore, are also more subject to work intensity ${ }^{(11,18)}$. 
The variables associated with work intensity in this study demonstrate that versatility and flexibility are current characteristics of nursing work in public hospitals in Bahia/ Brazil. However, studies carried out in other countries ${ }^{(19-23)}$ found that work intensity is a global phenomenon, and work versatility is its main characteristic.

Among the factors that intensify nursing work, understaffing stands out. This has become a common modus operandi in all institutions ${ }^{(4)}$. This reveals the adoption of flexibility in nursing work, that is, there is an increase in the number of patients and in the degree of complexity and, consequently, the care procedures required are always performed by less staff than necessary ${ }^{(4)}$.

Understaffing, associated with the variables related to versatility, puts at risk not only the health of the worker, but the patients themselves. The analysis of the ethical legal cases filed in the Regional Nursing Council of Bahia showed that, all the times that a worker made a mistake, the work intensity caused by understaffing was a causal factor (22). An American study on the impact of intensity and understaffing on patient safety revealed that, for every additional patient that was admitted to the investigated Intensive Care Unit (ICU), increasing the nurse's workload, the odds of patient mortality increased by $7 \%{ }^{(23)}$.

In this context of understaffing, in which the worker needs to take on multiple functions, other characteristics of toyotism appear. An intense work pace and time pressure can increase productivity at work, which has always been the objective in the capitalist mode of production $^{(1-3)}$.

Permanent workers do not get profit from selling their workforce. Therefore, for them, this increase in productivity means that nurses, technicians and assistants have high work demands, even though they do not always have the necessary conditions for this. Therefore, they partially meet the constraints of the State in the provision of hospital services ${ }^{(11,18)}$.

For outsourced workers, selling their workforce creates surplus value for the outsourcing companies. Thus, the increase in productivity and the understaffing allow companies to increase their profit ${ }^{(11,18)}$, given that they do not hire the necessary quantity of nurses, technicians and assistants and can extract more work from their staff, reaching the goals agreed with the State - their contractor.

However, a study on the outsourcing of nursing services in an Iranian public hospital revealed its lack of efficiency, mainly because after outsourcing the costs per bed increased, productivity decreased and a positive variation of $1 \%$ was found in customer satisfaction(24).

All variables analyzed can lead to physical and emotional exhaustion of nurses, technicians and assistants, and can also explain the desire to leave the profession expressed by these workers ${ }^{(25)}$, work-related illness $^{(26-27)}$ and/or professional errors ${ }^{(22,28)}$.

The similarity of the answers in the quartiles and medians and the lack of statistical difference in work Intensity score between permanent and outsourced nurses, technicians and assistants demonstrates that, regardless of the type of employment, work intensity is a fact for all these workers. Some studies in the area of sociology of work ${ }^{(29-31)}$ reveal that outsourced workers are more vulnerable to work intensity than other workers; however, this was not observed in this research.

The limitations of this study were the long data collection period, due to the conditions of the research field, and the fact that it was carried out only in public hospitals.

An advancement of scientific knowledge in the field of nursing that stands out in this study is the approach to work intensity as a central element for the precarization of work, revealing that this phenomenon is uneven for the three categories of workers. Therefore, specific studies on work and intensity according to the professional category should be performed.

\section{Conclusion}

For nursing workers in public hospitals in Bahia, work intensity was revealed by variables related to understaffing and versatility and flexibility in the execution of tasks and activities.

The results of the factor loadings demonstrate that work intensity variables vary between the professional categories and are related to the work performed. Therefore, for nursing technicians and assistants, the variables that most intensify work are those related to direct assistance; for nurses, the variables associated with the management of the work process are the most relevant.

The lack of statistically significant difference between the groups of outsourced and permanent workers in the precarization of labor by intensity score reveals that nurses, technicians and nursing assistants are subject to this condition in the hospitals of the Unified Health System.

Since intensity of work is one of the aspects of precarization, it will become more evident as work becomes more precarious, which for nursing work means long hours and low wages, but also understaffing, versatility and flexibility.

\section{References}

1. Cardoso ACM. D Right and obligation to disconnection striving for working and non-working time. Rev UFMG. 2016; 23(1,2): 62-85. doi: http://dx.doi.org/10.35699/2316$770 \times .2016 .2756$ 
2. Dal Rosso S, Cardoso ACM. Intensity of work: conceptual and methodological questions. Soc Estado. 2015; 30(3): 631-50. doi: http://dx.doi.org/10.1590/ S0102-69922015.00030003

3. Cardoso ACM. Organization and intensification of working time. Soc Estado. 2013; 28(2): 351-74. doi: http://dx.doi.org/10.1590/S0102-69922013000200009 4. Souza HS, Mendes AN. Outsourcing and "dismantling" of steady jobs at hospitals. Rev Esc Enferm USP. 2016; 50(2):284-91. doi: http://dx.doi.org/10.1590/S0080623420160000200015

5. Durand JP. Refoundation of work in the stressed stream. Tempo Soc. 2003;15(1):139-58. doi: http:// dx.doi.org/10.1590/S0103-20702003000100008

6. Machado MH, Aguiar W Filho, Lacerda WF, Oliveira E, Lemos W, Wermelinger $M$, et al. General characteristics of nursing: the socio-demographic profile. Enferm Foco. 2016; 7(SP):9-14. doi: http://dx.doi.org/10.21675/2357707X.2016.v7.nESP.686

7. Salvarani V, Rampoldi G, Ardenghi S, Bani M, Blasi P, Ausili $D$, et al. Protecting emergency room nurses from burnout: The role of dispositional mindfulness, emotion regulation and empathy. J Nurs Manag. 2019; 27:765- 74. doi: http://dx.doi.org/10.1111/jonm.12771

8. Kaur AP, Levinson AT, Monteiro JFG, Carino GP. The impact of errors on healthcare professionals in the critical care setting. J Crit Care. 2019; 52:16-21. doi: http://dx.doi.org/10.1016/j.jcrc.2019.03.001

9. Boekhorst JA, Singh P, Burke R. Work intensity, emotional exhaustion and life satisfaction: The moderating role of psychological detachment. Personnel Rev. 2017; 46(5):891-907. doi: http://dx.doi.org/10.1108/PR-052015-0130

10. Sülz S, Langhammer K, Becker-Peth M, Roth B. What drives perceived work intensity in neonatal intensive care units? Empirical evidence from a longitudinal. J Adv Nurs. 2017; 73(10):2441-9. doi: http://dx.doi. org/10.1111/jan.13301

11. Druck G. Labor, precarization and resistances: old and new challenges? Cad CRH. 2011; 24(spe 01):37-57. doi: http://dx.doi.org/10.1590/S0103-49792011000400004 12. Lahoz MA. Indicators of working conditions: perception of social actors. Ação Ergonômica. [Internet]. 2019 [cited Nov 4, 2019]; 13(1):163-85. Available from: http://www.abergo.org.br/revista/index.php/ae/ article/view/400/731731759

13. Damasio BF. Use of exploratory factorial analysis in psychology. Aval Psicol. [Internet]. 2012 [cited Dec 4, 2018];11(2):213-28. Available from: http:// pepsic.bvsalud.org/pdf/avp/v11n2/v11n2a07.pdf

14. Mendes JR, Lopes MCB, Vancini-Campanharo CR, Okuno MFP, Batista REA. Types and frequency of errors in the preparation and administration of drugs. Einstein.
2018; 16(3): 41-6. doi: http://dx.doi.org/10.1590/ s1679-45082018ao4146

15. Souza CS, Tomaschewski-Barlem JG, Rocha LP, Barlem ELD, Silva TL, Neutzling BRS. Patient safety culture in intensive care units: perspective of health professionals. Rev Gaúcha Enferm. 2019; 40(spe):1-9. doi: http://dx.doi. org/10.1590/1983-1447.2019.20180294

16. Steege LM, Pinekenstein BJ, Rainbow JG, Arsenault Knudsen É. Addressing Occupational Fatigue in Nurses: Current State of Fatigue Risk Management in Hospitals. J Nurs Adm. 2017;47(9):426-33. doi: http://dx.doi. org/10.1097/NNA.0000000000000509

17. Udod SA, Cummings G, Care WD, Jenkins $M$. Impact of Role Stressors on the Health of Nurse Managers: A Western Canadian Context. J Nurs Adm. 2017;47(3):159-64. doi: http://dx.doi.org/10.1097/ NNA.0000000000000459

18. Druck G. Unrestrained outsourcing in Brazil: more precarization and health risks for workers. Cad Saúde Pública. 2016; 32(6):1-9. doi: http://dx.doi. org/10.1590/0102-311X00146315

19. Basu H. Deregulation, workplace, and women: Nurses in private health care in India. Asian Soc Work Policy Rev. 2019; 13(2): 179-88. doi: http://dx.doi. org/10.1111/aswp.12168

20. Sierakowska M, Doroszkiewicz H, Kondzior D, Klimaszewska K, Jemieljańczuk Z, Dolińska C. Prevention of the musculoskeletal system's dysfunction based on the example of Prevention Program of Spinal Pain Syndrome in Nursing Staff. Medycyna Pracy. 2019; 70(2):189-99. doi: http://dx.doi.org/10.13075/mp.5893.00801

21. Cañadas-De la Fuente GA, Albendín-García $L$, Cañadas GR, San Luis-Costas C, Ortega-Campos E, de la Fuente-Solana EI. Nurse burnout in critical care units and emergency departments: Intensity and associated factors. Emergencias. [Internet]. 2018 [cited Nov 15, 2018];30(5):328-31. Available from:http://emergencias. portalsemes.org/numeros-anteriores/volumen-30/ numero-5/nurse-burnout-in-critical-care-units-andemergency-departments-intensity-and-associatedfactors/english/

22. Silva-Santos H, Araújo-dos-Santos T, Alves AS, Silva MN, Costa HOG, Melo CMM. Error-producing conditions in nursing staff work. Rev Bras Enferm. 2018; 71(4):185864. doi: http://dx.doi.org/10.1590/0034-7167-2017-0192 23. Aiken LH, Clarke SP, Sloane DM, Sochalski J, Silber $\mathrm{JH}$. Hospital nursing staffing and patient mortality, nurse burnout, and job disssatisfaction. JAMA. 2002; 288(16):1987-93.doi: http://dx.doi.org/10.1001/ jama.288.16.1987

24. Ferdosi M, Farahabadi E, Mofid M, Rejalian F, Haghighat M, Naghdi P. Evaluation of Outsourcing in Nursing Services: A Case Study of Kashani Hospital, 
Isfahan in 2011. Materia Socio-Medica. 2013; 25(1):37-9. doi: http://dx.doi.org/10.5455/msm.2013.25.37-39

25. Lee YW, Dai YT, Park CG, McCreary LL. Predicting quality of work life on nurses intention to leave. J Nurs Scholarship. 2013; 45(2):160-8. doi: http://dx.doi. org/10.1111/jnu.12017

26. Nogueira LS, Sousa RMC, Guedes ES, Santos MA, Turrini RNT, Cruz DALM. Burnout and nursing work environment in public health institutions. Rev Bras Enferm. 2018;71(2):336-42. doi: http://dx.doi. org/10.1590/0034-7167-2016-0524

27. Guirardello EB. Impact of critical care environment on burnout, perceived quality of care and safety attitude of the nursing team. Rev. Latino-Am. Enfermagem. 2017;25:e2884. doi: http://dx.doi.org/10.1590/15188345.1472.2884

28. Bae SH, Fabry D. Assessing the relationships between nurse work hours/overtime and nurse and patient outcomes: systematic literature review. Nurs Outlook. 2014;62:138-56. doi: http://dx.doi. org/10.1016/j.outlook.2013.10.009

29. Carvalho LV, Bridi MA. Work and inequality: the outsourcing and their effects on workers. Rev ABET. [Internet]. 2015 [cited Out 20, 2018];14(1):99-113. Available from:http://periodicos.ufpb.br/ojs/index.php/ abet/article/view/25703

30. Druck G. The outsourcing in public health: various forms of precarization of labor. Trab Educ Saúde. 2016;14(supl. 1):15-43. doi: http://dx.doi. org/10.1590/1981-7746-sol00023

31. Valle K, Leite JL. Admirable new world: precarization / intensification of the work on the public employee. Temporalis. 2016; 15(30):161-82. doi: http://dx.doi. org/10.22422/2238-1856.2015v15n30p161-182 Creative Commons (CC BY).

This license lets others distribute, remix, tweak, and build upon your work, even commercially, as long as they credit you for the original creation. This is the most accommodating of licenses offered. Recommended for maximum dissemination and use of licensed materials. 